\title{
HIV/AIDS, declining family resources and the community safety net
}

\author{
Jody Heymann ${ }^{\mathrm{a}, \mathrm{b}, \mathrm{c}}$ and Rachel Kidman ${ }^{\mathrm{a}, \mathrm{b} *}$ \\ ${ }^{a}$ Institute for Health and Social Policy, McGill University, 1130 Pine Avenue West, Montreal H3A 1A3, Canada; ${ }^{b}$ Department \\ of Epidemiology, Biostatistics, and Occupational Health, McGill University, 1130 Pine Avenue West, Montreal H3A 1A3, \\ Canada; 'Department of Political Science, McGill University, 1130 Pine Avenue West, Montreal H3A 1A3, Canada
}

(Received 19 December 2008; final version received 25 March 2009)

\begin{abstract}
Families play central roles in the HIV/AIDS pandemic, caring for both orphaned children and the ill. This extra caregiving depletes two family resources essential for supporting children: time and money. We use recent data from published studies in sub-Saharan Africa to illustrate deficits and document community responses. In Botswana, parents caring for the chronically ill had less time for their preschool children (74 versus 96 hours per month) and were almost twice as likely to leave children home alone ( $53 \%$ versus $27 \%)$; these children experienced greater health and academic problems. Caregiving often prevented adults from working full time or earning their previous level of income; $47 \%$ of orphan caregivers and $64 \%$ of HIV/AIDS caregivers reported financial difficulties due to caregiving. Communities can play an important role in helping families provide adequate childcare and financial support. Unfortunately, while communities commonly offer informal assistance, the value of such support is not adequate to match the magnitude of need: $75 \%$ of children's families in Malawi received assistance from their social network, but averaging only US\$81 annually. We suggest communities can strengthen the capacity of families by implementing affordable quality childcare for 0-6 year olds, after-school programming for older children and youth, supportive care for ill children and parents, microlending to enhance earnings, training to increase access to quality jobs, decent working conditions, social insurance for the informal sector, and income and food transfers when families are unable to make ends meet.
\end{abstract}

Keywords: HIV/AIDS; family; community; intervention; children

\section{Introduction}

The HIV/AIDS pandemic has left millions of children without adequate care and support. In sub-Saharan Africa alone, there are an estimated 12 million orphans due to AIDS, and two million children are infected with HIV (UNAIDS, 2008). Many more are made vulnerable when AIDS affects their families, including children living with chronically ill parents.

Families are best placed to support children and have made tremendous efforts in the current crisis, taking up both the care of orphaned children and of children and adults suffering AIDS-related illness (Deininger, Garcia, \& Subbarao, 2003; Mutangadura, 2001; Office of the President and Cabinet, Republic of Malawi, 2008; UNAIDS, 2004). This extra responsibility, however, depletes two family resources essential for supporting children's healthy development: time and money. Communities have traditionally played an important role in helping families fill these deficits (Foster, 2004; Mutangadura \& Makaudze, 2000; World Bank, 1997), but this safety net may be disintegrating under the strain of the current crisis (Foster, 2005; Mtika, 2001; Ntozi \& Zirimenya, 1999). Evidence suggests that in the context of the AIDS pandemic, far too little support is being provided relative to the magnitude of need.

We use recent data from Botswana and Malawi to provide insights into the resource needs of caregiving families, and into how communities are responding. We conclude by tackling a critical question: what does this evidence tell us about how communities can strengthen the capacity of families to deliver care to children affected by HIV/AIDS?

\section{Methods}

We use quantitative studies from two countries. Botswana, previously an example of economical prosperity in Africa, has seen its gains all but swept away by a staggeringly high HIV prevalence (24\%) and now is home to 95,000 orphans (UNAIDS, 2008). Data are drawn from the Botswana Family Health Needs Study (Heymann, 2006; Heymann, Earle, Rajaraman, Miller, \& Bogen, 2007; Miller, Gruskin, Subramanian, Rajaraman, \& Heymann, 2006; Rajaraman, Earle, $\&$ Heymann, 2008). This study sampled working adults with caregiving responsibilities who used government health centers. Questionnaires focused on issues

*Corresponding author. Email: rachel.kidman@mail.mcgill.ca 
surrounding family health needs, caregiving, and working. Of the 1033 adults in our sample, $177(17 \%)$ reported caring for someone who was HIV-positive and $379(37 \%)$ reported caring for at least one orphan (i.e., any child $0-17$ years who had lost at least one parent). Both because of the importance of care they provide in addressing the epidemic, and because of its impacts on their own and their families' lives, we surveyed adults who were caring for orphans living outside their households, as well as those who were caring for orphans within their household. Adults who are caring for orphans living outside their households often do so because the household head cannot provide sufficient care (e.g., the head is a child or youth themselves, is elderly or disabled, or the caregiving burden exceeds their resources).

Malawi, one of the poorest countries globally, now struggles with a $14 \%$ HIV prevalence and an additional 560,000 orphans due to AIDS (UNAIDS, 2008). We use data from the 2004-2005 Malawi Integrated Household Survey administered by the National Statistics Office of Malawi (National Statistics Office, 2005a, 2005b). Household questionnaires collected detailed information on 27,495 children in 9331 households in 564 communities; community questionnaires were also administered to residents knowledgeable about their community and a consensus response was recorded (National Statistics Office, 2005b). In the sample restricted to families, $17 \%$ of households contained at least one orphan, and $19 \%$ of households had an adult member aged 18-59 years who was chronically ill.

These two countries represent the range of economic conditions in sub-Saharan Africa, with Malawi being the poorest non-conflict country and Botswana being historically amongst the economically strongest; they similarly allow one to look at the contrasting experiences of a country with relatively large national and international investment in government programs in the African context and of a country with relatively low investment from both sources.

In addition, our paper is informed by case studies of community programs that serve children affected by HIV/AIDS. Between 2005 and 2008, we conducted interviews with directors, staff, volunteers, caregivers, and community leaders at programs in Botswana, Malawi, and South Africa (e.g., Kidman, Petrow, \& Heymann, 2007).

\section{HIV/AIDS and declining family resources}

Families are the first line of protection for children and form the core safety net for orphans in subSaharan Africa (Bhargava et al., 2003; Chirwa, 2002; Madhavan, 2004; Smart, 2003; UNDP Malawi, 2006;
UNICEF, UNAIDS, \& USAID, 2004). However, this safety net is beginning to disintegrate in the context of HIV/AIDS (Aspaas, 1999; Bicego, Rutstein, \& Johnson, 2003; Chirwa, 2002; Mtika, 2001; Nyambedha, Wandibba, \& Aagaard-Hansen, 2003). In places with severe epidemics, households are losing working adults at the same time as orphans swell dependency ratios (Rivers, Silvestre, \& Mason, 2004). Families now face multiple caregiving responsibilities - for their own children, orphans they foster, and chronically ill family members. HIV-infected parents, once the primary source of care for their children, often need to become the primary recipient. These additional responsibilities severely deplete both the time adults can spend with children and the financial resources available to meet essential needs. As a result, families' ability to protect orphans and other children has been severely compromised (Mtika, 2001; Nyambedha et al., 2003; Aspaas, 1999).

\section{Adult time poverty}

The AIDS pandemic has left millions of children without the essential time they need with adults. While the loss of parents places orphans particularly at risk, they are not the only children affected. When parents are critically ill, their health limits the amount and quality of care they can provide. Parents caring for orphaned children or for chronically ill family members also have far less time for their own children. Markedly under recognized, this time poverty is of enormous consequence for children's daily lives, their health, and their education. The following data from Botswana illustrate the pandemic's contribution to time poverty.

After providing care to ill relatives, friends, and neighbors, we found that parents had less time for their own children (Rajaraman et al., 2008). This deficit was most pronounced for children under six: parents with additional HIV/AIDS caregiving responsibilities spent 22 hours less per month with their young children (Heymann, 2006).

To fill this gap, older siblings often provided childcare. This simultaneously lowered the quality of care that young children received and jeopardized the welfare of older children. Older siblings (6-14 years) often had to forgo school in order to provide childcare. This situation was far more common in families caring for people living with AIDS (15\% versus 9\%; Figure 1) (Heymann, 2006). When older children were not available to substitute for parents, we found parents often had no choice but to leave children home alone: $53 \%$ of HIV/AIDS caregivers reported that they left children under five years home alone (Figure 1) (Heymann, 2006). 


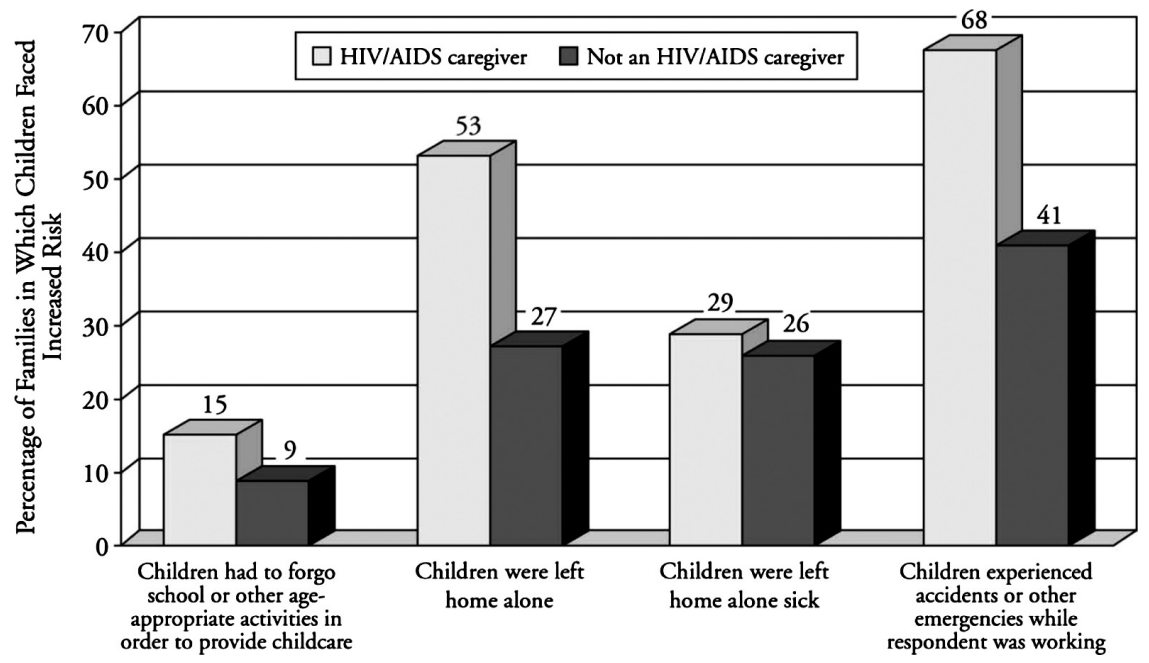

Figure 1. Children of HIV/AIDS caregivers in Botswana face heightened risks; figure reproduced from Heymann (2006).

Parents expressed deep concern about the welfare of their children when they were not able to provide care. HIV/AIDS caregivers, orphan caregivers, and HIV-infected parents all expressed concern about the quality of childcare while they were at work $(36,41$, and $48 \%$, respectively) (Heymann, 2006; Heymann et al., 2007; Rajaraman et al., 2008). Concern intensified when the child in question was HIVinfected: $72 \%$ of caregivers for an HIV-infected child worried about the quality of childcare; this rose to $89 \%$ when the child was ill (Heymann, 2006). In the absence of quality childcare, orphan caregivers were more likely than other parents to worry that their children were not receiving adequate educational and developmental support (32\% versus $21 \%$ ) and emo- tional support ( $35 \%$ versus $23 \%$ ) while they were at work (Heymann et al., 2007). Similarly, HIV-infected parents were more likely than non-infected parents to report worrying that their children were not receiving adequate educational and developmental support $(39 \%$ versus $25 \%)$ or adequate emotional support (39\% versus 27\%) (Heymann, 2006).

Parents' concerns were well founded. In our sample, $68 \%$ of children whose parents were HIV/ AIDS caregivers experienced accidents and emergencies while their parents were working away from home, compared to $41 \%$ of other children (Figure 1) (Heymann, 2006). The long-term impact of diminished time and financial resources was also evident: the children of HIV/AIDS caregivers were more

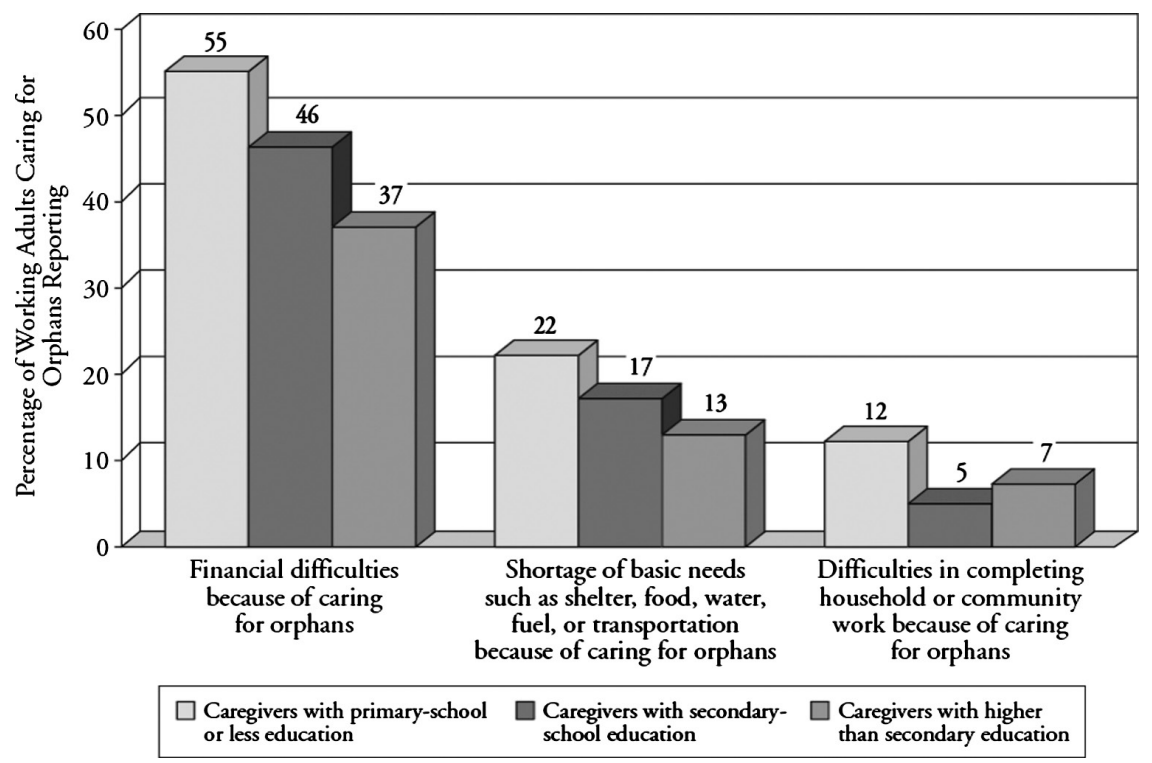

Figure 2. Orphan caregivers face greater financial problems due to caregiving; figure reproduced from Heymann (2006). 
likely to suffer from poor health (43\% versus $28 \%$ ); experience emotional/behavioral difficulties $(19 \%$ versus $14 \%)$; drop out of school $(18 \%$ versus $11 \%)$; and have academic problems (18\% versus 13\%) (Rajaraman et al., 2008).

\section{Economic impoverishment}

When parents suffer AIDS-related illnesses, children are deprived of more than adult time; they are also deprived of financial resources essential for their welfare. Greater medical costs, combined with loss of work, drain resources away and are detrimental to child welfare. In our sample, $48 \%$ of HIV-positive adults experienced health-related financial difficulties, while $23 \%$ reported profound difficulties in obtaining food, water, fuel, and transportation (Heymann, 2006).

When families take on additional caregiving responsibilities without additional income, financial difficulties also mount. Approximately half (47\%) of the orphan caregivers and $64 \%$ of the HIV/AIDS caregivers surveyed in Botswana reported financial difficulties due to extra caregiving (Heymann, 2006; Miller et al., 2006); these hardships were greatest among caregivers with only a primary-school education (Figure 2) (Heymann, 2006).

In the context of the maturing epidemic, families are likely to experience repeated HIV/AIDS-related crises. It is neither unusual to foster orphans from multiple families, nor to simultaneously be caring for people living with AIDS. Each additional caregiving responsibility increases the likelihood that the family will experience financial difficulties. Families fostering three or more orphans were twice as likely as those fostering one to experience financial difficulties (Miller et al., 2006).
Additional caregiving often prevented adults from being able to work full time or earn their previous income. In our study, HIV/AIDS caregivers were more likely to take leave from work to provide care than other parents ( $53 \%$ versus $39 \%$ ), and this leave was more likely to be unpaid $(54 \%$ versus $38 \%$ ) (Rajaraman et al., 2008). With greater demands on their time, orphan caregivers had less flexibility to work overtime: only $18 \%$ of orphan caregivers versus $26 \%$ of other working adults worked overtime at least once a week (Heymann et al., 2007). Conflicts between caregiving and work also jeopardized child welfare: $47 \%$ of orphan caregivers said their work got in the way of meeting children's needs compared to only $30 \%$ who were not caring for orphans (Heymann et al., 2007).

\section{What communities are doing to support families}

Traditionally, communities provided valuable assistance in times of need. In the wake of the AIDS pandemic, it is unclear to what degree communities are too overburdened to work alone to strengthen families.

In Botswana, $43 \%$ of orphan caregivers received help from other household members, and 39\% received help from relatives outside their home (Figure 4). Among relatives outside home, 67\% assisted economically, 58\% provided material help (e.g., food, clothing), $46 \%$ provided educational support, $28 \%$ provided emotional support, and $21 \%$ assisted with childcare (Heymann et al., 2007). Organized responses by either a local traditional council or the national government reached a third of all families fostering orphans (Figure 3) (Heymann et al., 2007). Other members of the community rarely ( $2 \%$ or less)

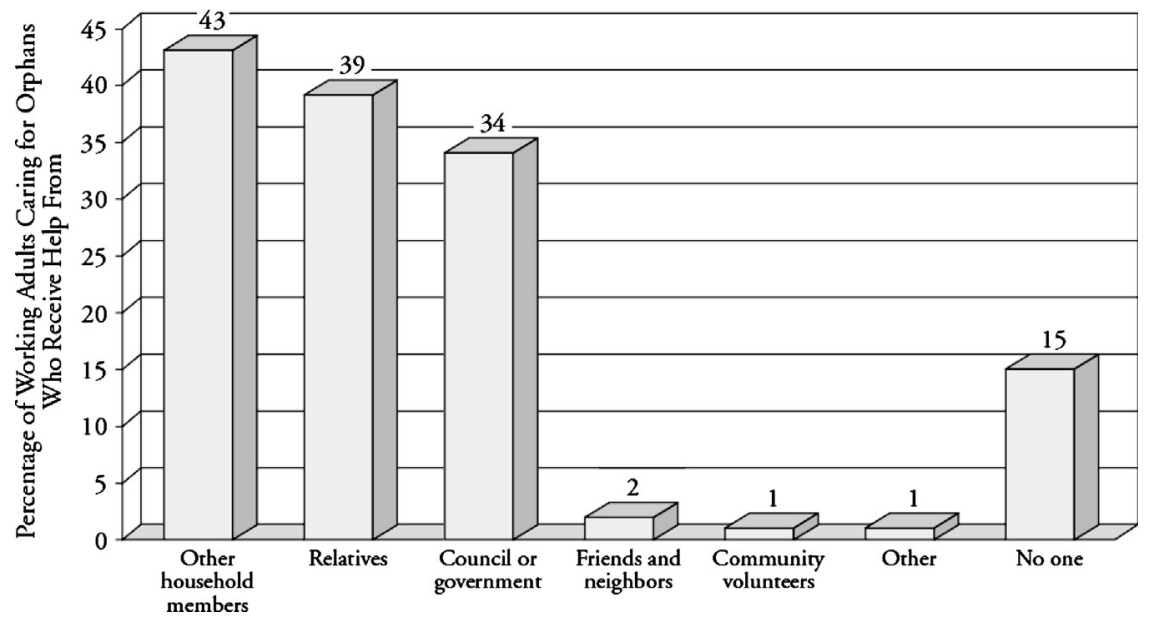

Figure 3. Working adults' sources of support in caring for orphans; figure reproduced from Heymann (2006). 


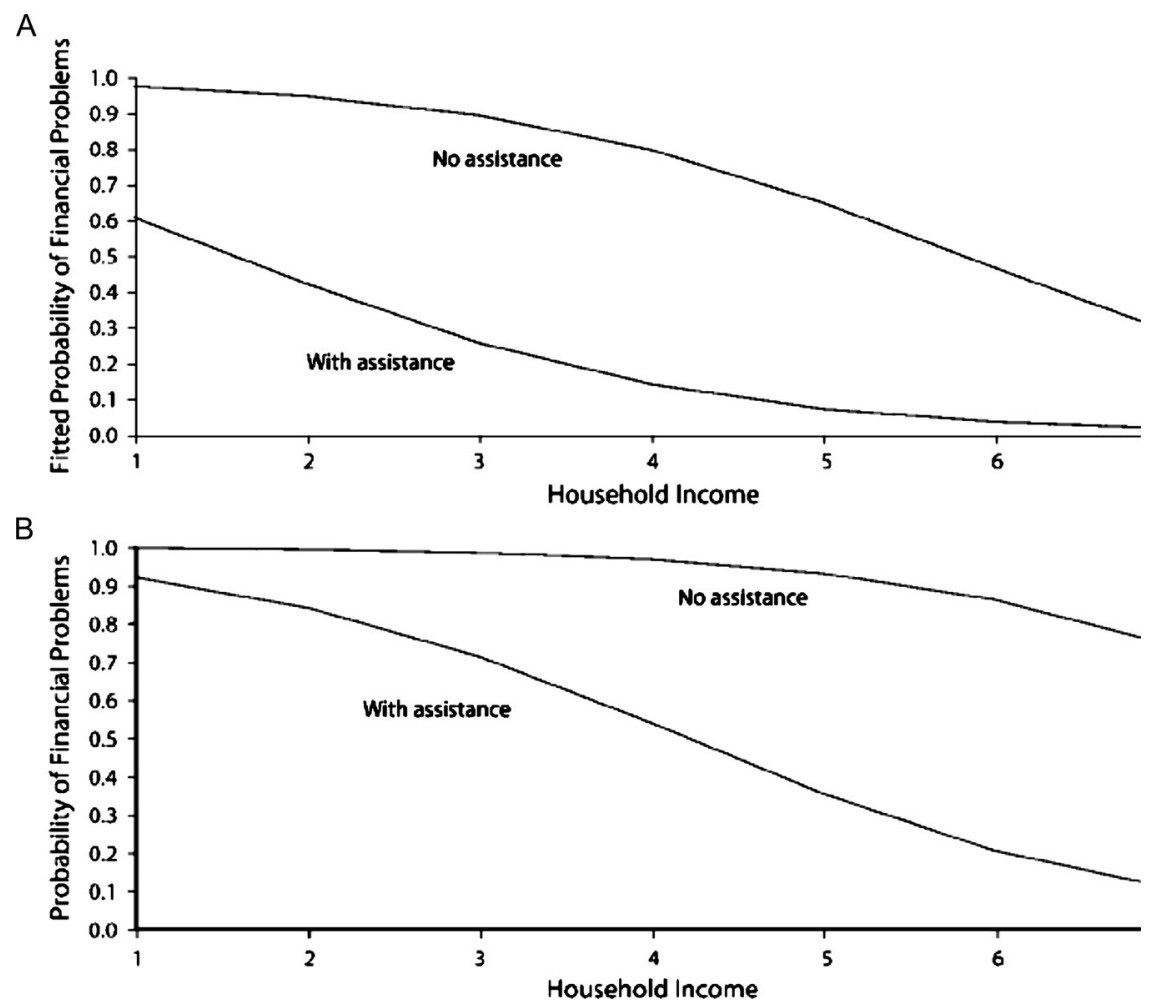

Figure 4. Estimated probability that a household will have financial difficulties because of orphan care based on income level and receiving orphan assistance in households not caring (a) and caring (b) for adults; figure reproduced from Miller, Gruskin, Subramanian, Rajaraman, and Heymann (2006).

offered any support to orphan caregivers (Heymann et al., 2007).

In Malawi, $75 \%$ of children lived in households that had received food, cash, or gifts in the past year from relatives, friends, and neighbors, but the value of such support was relatively low (averaging US\$81 annually) (Kidman \& Heymann, 2009); it was not possible to differentiate gifts given by relatives versus friends. Families caring for double orphans were $42 \%$ more likely to receive private transfers of support (Kidman \& Heymann, 2009). Poor families with uneducated heads received transfers of lesser value than other groups (Kidman \& Heymann, 2009). Only $40 \%$ of children lived in communities which had a

Table 1. Community initiatives that address families' time and economic burdens.

Targeting time poverty

Community-based day care centers

After-school programs

Home-based care programs

Targeting economic poverty

Microfinance programs

Job skill training

Workplace policies

Social insurance groups

Community gardens and grain banks
Provide a safe environment for children aged 0-6 years and enable adults to work

Provide important academic and emotional support to children and youth while enabling adults to work

Enable parents living with AIDS or caring for the chronically ill to spend more time with their children and continue to work.

Help families realize higher returns for their labor and invest in their children's health and education

Provides a critical stepping stone to better paid jobs

Provide flexible schedules and paid leave to care for sick children and adults while continuing to earn an income

Help informal workers to cover expenses if illness requires them to temporarily stop working

Generate extra resources for distribution to the most vulnerable families 
community-based support group for the chronically ill (Kidman \& Heymann, 2009); information was not available on how many children actually benefited from these groups.

While the different data available on Botswana and Malawi do not allow a direct comparison, it is clear that in both cases only a minority of children had access to needed support. Assistance gaps mattered to the family's welfare. For many households in Botswana with only orphan caregiving responsibilities, external assistance kept financial difficulties at bay (Figure 4a) (Miller et al., 2006). For poor households with both orphan and HIV/AIDS caregiving burdens (Figure 4b), however, the level of external assistance was not high enough to protect them from financial difficulties (Miller et al., 2006).

\section{Solutions within reach}

Children affected by the HIV/AIDS pandemic need to be assured of adequate care. Families are best placed to deliver this care, yet many are currently overburdened and urgently need interventions that strengthen their ability to provide for these children. There is a strong international consensus on the importance of providing families with support needed, as reflected in the widely endorsed Framework for the Protection, Care and Support of Orphans and Vulnerable Children Living in a World with HIV and AIDS (UNICEF et al., 2004). Still, a great deal more needs to be done on the ground to implement solutions and strengthen families. This section focuses on those approaches that are most urgently needed to address families' time and economic burdens, and which could be effectively and feasibly implemented by communities (Table 1).

To alleviate time poverty, we suggest greater investment in affordable quality childcare for 0-6 year olds, after-school programming for older children, and supportive care for chronically ill children and adults. Quality childcare can free up time for adults to engage in economically productive labor and eliminate the need to withdraw older siblings from school to provide childcare. Moreover, quality early childhood interventions can ensure children's nutritional, health, cognitive, and emotional well-being (Deutsch, 1998), as well as greater progression through school and better employment in adulthood (Castaneda, 1999; Engle et al., 2007; GranthamMcGregor et al., 2007; Walker et al., 2007). A range of community-based models have arisen that can be effective in helping families care for young children (Kidman et al., 2007). Malawi has initiated a nationwide movement to mobilize and capacitate community-based childcare (Malawi Government \&
UNICEF, 2007a,b). Community members serve as volunteer caregivers, and usually donate both materials and labor for the construction of the childcare center. In turn, the government with assistance from UNICEF provides necessary technical training in early childhood development and psychosocial care for the caregivers. In the townships outside of Cape Town, South Africa, the NGO Ikamva Labantu supports a network of 250 crèches and strengthens the crèches' ability to care for children's needs. They also supply food, basic necessities, access to medical care, and home-based care directly to the family (Kidman et al., 2007).

Communities can address caregivers' concern that their school-age children do not have access to adequate educational and emotional support by organizing after-school and weekend programs. These programs should actively encourage the involvement of adolescents - a population often neglected in the global response but who need and want adults in their life to guide them through the transition to adulthood. Consol Homes Orphan Care $^{1}$ in Malawi provides a good example. Their afternoon program includes homework and developmental activities integrated with programs designed to address physical and mental health needs and HIV prevention. Through Orphan Affairs Units, older orphans have leadership opportunities to run their own council, provide counseling to their peers, and solve problem for their own communities - all under the guidance and support of adults. Having started in one community, Consol Homes has now expanded its services to 15,000 school-age children and youth in 50 communities. A similar expansion is underway throughout the country since the government of Malawi has simultaneously been working to capacitate community programs that reach school-age children.

Our research has shown that caregiving for the chronically ill also deprives children of essential time with adults and interferes with the family's ability to generate income. Communities can alleviate this caregiving burden through home-based care programs (Ogden, Esim, \& Grown, 2006). Basic medical care, education on nutrition and healthy living, help with domestic chores, and emotional support to both the patient and the caregiver are all essential elements of comprehensive home-based care programs. For parents living with AIDS, this essential care can help them maintain their health, and greatly increase the amount of quality time they have with their children. For families nursing the chronically ill, home-based care programs can enable them to spend the extra time with children or in income-generating activities. 
In addition to addressing time poverty, each of these programs supports adult caregivers' ability to earn income. Economic security can be further strengthened with microlending to enhance earnings by families, training to increase access to quality jobs, establishing decent working conditions, social insurance for the informal sector, and income and food transfers.

In microcredit associations, members are eligible to borrow money from the communal savings pool to start small businesses. This enables families to realize higher returns for their labor. As a result, credit and savings programs have attracted women in unprecedented numbers (Chen et al., 2005). Moreover, women invest their savings in their children, leading to better nutrition and educational outcomes (Barnes, 2001; Barnes, Gaile, \& Kibombo, 2001; Chen \& Snodgrass, 2001; Chowdhury \& Bhuiya, 2001; Khandker, 1998; Todd, 1996). For example, the Village Savings and Loan Microfinance Program (part of the Livingstonia Synod AIDS Program in Ekwendani, Malawi) establishes and capacitates community-based credit associations open to the whole community; $83 \%$ of its participants are women. This and other forms of village microfinance can play a crucial role in ensuring families a route to earn their way out of poverty.

Communities can also help families achieve greater economic security by initiating programs to increase job skills. While training programs are increasingly being developed for youth affected by HIV/AIDS, more can be done to increase opportunities for the current generation of caregivers. This may mean enabling them to complete their education or vocational programs. Some excellent examples already exist for youth, including within the Malawi Children's Village. $^{2}$ They ensure students in their catchment communities can finish secondary school by providing academic support and scholarships; they also provide vocational training to ensure sustainable livelihoods for those not attending secondary school.

Once caregivers have paid work, communities can influence working conditions that affect their ability to earn while caregiving. Caregivers should not have to choose between staying home with a sick family member and having a job. The local business community has an important role to play. Local businesses can offer flexible schedules and paid leave to care for sick children and adults. For HIV-positive individuals, flexible hours would accommodate critical medical appointments and paid leave would enable them to take time off to recuperate when they fall ill. Nondiscrimination in hiring practices, which can be monitored and enforced by the community, would secure the job opportunities for HIV-positive individuals in a context where significant stigma still remains. For a discussion on the ability of companies to do this while economically succeeding, please see Petrow, Simmons, and Heymann (2007).

Community action is equally essential for those working in the informal economy, which is rarely governed by legal statutes. Communities can help informal workers form social insurance groups to cover expenses if serious illness - their own or their children's - requires them to temporarily stop working. This can be a separate program, or be bundled with credit and savings associations (e.g., microinsurance by the Self-Employed Women's Association in India; Panjaitan-Drioadisuryo \& Cloud, 1999). In the Village Savings and Loan Microfinance Program, families contribute a set amount toward a social fund every month. Rather than deplet their meger savings of sell productive assets in times of crisis, families can borrow from this fund (without interest) to ensure that their children's essential needs are met.

While most people prefer to earn their way out of poverty, there will be times when stopgap measures are necessary (e.g., non-earning periods while in training, when disability/illness prevents working, or when elderly caregivers are past working age). Governments will need to take responsibility for much of this support, likely in the form of cash transfers that would allow families to purchase health care, education, childcare, and other services. At the same time, rural communities can generate extra resources for distribution to the most vulnerable families through community gardens and grain banks.

By implementing the above programs, communities and policy makers can help families provide adequate care and earn enough to support children. The success of these programs will require volunteers and resources from within the community, but also that technical and financial support be made available to these communities.

Communities are themselves overwhelmed and under resourced, and cannot be expected to act in isolation. States, non-governmental organizations, and international donors have the human and financial resources to mobilize and sustain community responses on the scale required. Ultimately, building strong families will require the combined efforts of many small, local communities, large national ones, and one very large international community.

\section{Notes}

1. For more information see www.consolhomes.org.

2. For more information see www.malawichildrensvillage. com. 


\section{References}

Aspaas, H.R. (1999). AIDS and orphans in Uganda: Geographical and gender interpretations of household resources. The Social Science Journal, 36(2), 201-226.

Barnes, C. (2001). Microfinance program clients and impact: An assessment of Zambuko trust, Zimbabwe. Washington, DC: The AIMS Project, USAID.

Barnes, C., Gaile, G., \& Kibombo, R. (2001). The impact of three microfinance programs in Uganda. Uganda, Africa: The Assessing the Impact of Microenterprise Services (AIMS) Project, USAID.

Bhargava, A., \& Bigombe, B. (2003). Public policies and the orphans of AIDS in Africa. BMJ, 326(7403), 13871389.

Bicego, G., Rutstein, S., \& Johnson, K. (2003). Dimensions of the emerging orphan crisis in sub-Saharan Africa. Social Science \& Medicine, 56, 1235-1247.

Castaneda, T., \& Aldaz-Carroll, E. (1999). The intergenerational transmission of poverty: Some causes and policy implications. Inter-American Development Bank Discussion Paper. Retrieved July 2008, from http://www. iadb.org/sds/doc/1258eng.pdf.

Chen, M., Vanek, J., Lund, F., Heintz, J., Jhabvala, R., \& Bonner, C.h. (2005). Progress of the world's women 2005: Women, work and poverty. New York: United Nations Development Fund for Women.

Chen, M.A., \& Snodgrass, D. (2001). Managing resources, activities, and risk in urban India: The impact of SEWA Bank. Retrieved October, 2007. from http://www. usaidmicro.org/pubs/aims

Chirwa, W. (2002). Social exclusion and inclusion: Challenges to orphan care in Malawi. Nordic Journal of African Studies, 11(1), 93-113.

Chowdhury, A.M.R., \& Bhuiya, A. (2001). Do poverty alleviation programmes reduce inequity in health: Lessons from Bangladesh? In D. Leon \& G. Walt (Eds.), Poverty inequity and health (pp. 312-332). Oxford: Oxford University Press.

Deininger, K., Garcia, M., \& Subbarao, K. (2003). AIDSinduced orphanhood as a systemic shock: Magnitude, impact, and program interventions in Africa. World Development, 31(7), 1201-1220.

Deutsch, R. (1998). How early childhood interventions can reduce inequality: An overview of recent findings. Washington, DC: Inter-American Development Bank.

Engle, P.L., Black, M.M., Behrman, J.R., de Mello, M.C., Gertler, P.J., Kapiriri, L., et al. (2007). Child development in developing countries 3: Strategies to avoid the loss of developmental potential in more than 200 million children in the developing world. Lancet, 369(9557), 229-242.

Foster, G. (2004). Safety nets for children affected by HIV/ AIDS in southern Africa. In R. Pharoah (Ed.), $A$ generation at risk: HIV/AIDS, vulnerable children and security in Southern Africa (pp. 65-92). Capetown, South Africa: ISS.

Foster, G. (2005). Under the radar: Community safety nets for children affected by HIV/AIDS in poor households in sub-Saharan Africa. Zimbabwe: UNRISD, 2002.
Grantham-McGregor, S., Cheung, Y., Cuento, S., Glewwe, P., Richter, L., Strupp, B., et al. (2007). Child development in developing countries 1: Developmental potential in the first 5 years for children in developing countries. Lancet, 369, 60-70.

Heymann, J. (2006). Forgotten families. New York: Oxford University Press.

Heymann, J., Earle, A., Rajaraman, D., Miller, C., \& Bogen, K. (2007). Extended family caring for children orphaned by AIDS: Balancing essential work and caregiving in a high HIV prevalence nations. AIDS Care, 19(3), 337-345.

Khandker, S. (1998). Fighting poverty with microcredit. Dhaka, Bangladesh: University Press.

Kidman, R., \& Heymann, J. (2009). The extent of community and public support available to families caring for orphans in Malawi. AIDS Care, 21(4), 439-447.

Kidman, R., Petrow, E., \& Heymann, S. (2007). Africa's orphan crisis: Two community-based models of care. AIDS Care, 19(3), 326-329.

Madhavan, S. (2004). Fosterage patterns in the age of AIDS: Continuity and change. Social Science \& Medicine, 58(7), 1443-1454.

Malawi Government \& UNICEF. (2007a). Communitybased childcare centres in Malawi: Past, present and future. Lilongwe: UNICEF.

Malawi Government, \& UNICEF. (2007b). Communitybased childcare profile. Lilongwe: UNICEF.

Miller, C., Gruskin, S., Subramanian, S., Rajaraman, D., \& Heymann, S. (2006). Orphan care in Botswana's working households: Growing responsibilities in the absence of adequate support. American Journal of Public Health, 96, 1429-1435.

Mtika, M. (2001). The AIDS epidemic in Malawi and its threat to household food security. Human Organization, 60(2), 178-188.

Mutangadura, G. (2001). Women and AIDS in Southern Africa: The case of Zimbabwe and its policy implications. Jenda: A Journal of Culture and African Women Studies, 1(2), 1-11.

Mutangadura, G., \& Makaudze, E. (2000). Urban vulnerability to income shocks and effectiveness of current social protection mechanisms: The case of Zimbabwe. Consultancy report submitted to the Ministry of Public Service, Labour and Social Welfare and the World Bank.

National Statistics Office. (2005a). Integrated household survey, 2004-2005: Vol I - household socio-economic characteristics. Zomba: Author.

National Statistics Office. (2005b). Malawi second integrated household survey (IHS-2) 2004-2005: Basic information document. Zomba: Author.

Ntozi, J., \& Zirimenya, S. (1999). Changes in household composition and family structure during the AIDS epidemic in Uganda. In: I. Orubuloye, J. Caldwell, \& J. Ntozi (Eds.), The continuing African HIV/AIDS epidemic (pp. 193-209). Canberra: Health Transition Centre, National Centre for Epidemiology and Population Health, Australian National University. 
Nyambedha, E., Wandibba, S., \& Aagaard-Hansen, J. (2003). Changing patterns of orphan care due to the HIV epidemic in western Kenya. Social Science \& Medicine, 57, 301-311.

Ogden, J., Esim, S., \& Grown, C. (2006). Expanding the care continuum for HIV/AIDS: Bringing carers into focus. Health Policy and Planning, 21(5), 333-342.

Panjaitan-Drioadisuryo, R.D.M., \& Cloud, K. (1999). Gender, self-employment and microcredit programs an Indonesian case study. The Quarterly Review of Economics and Finance, 39, 769-779.

Petrow, E., Simmons, S., \& Heymann, J. (2007). AIDS and working adults: The need for both public and private sector responses. McGill International Journal of Sustainable Development Law and Policy, 3(1), 103-118.

Rajaraman, D., Earle, A., \& Heymann, J. (2008). Working HIV caregivers in Botswana: Spill-over effects on work and family well-being. Community. Work and Family, 11(1), 1-17.

Republic of Malawi, Office of the President and Cabinet. (2008). Malawi HIV and AIDS monitoring and evaluation report 2007. Office of the President and Cabinet, Dept. of Nutrition, HIV and AIDS: Lilongwe, Malawi.

Rivers, J., Silvestre, E., \& Mason, J. (2004). Nutritional and food security status of orphans and vulnerable children. Report of a Research Project supported by UNICEF, IFPRI, and WFP. Tulane University School of Public Health and Tropical Medicine: New Orleans.
Smart, R. (2003). Policies for orphans and vulnerable children: A framework for moving ahead. Washington, DC: US Agency for International Development Policy Project.

Todd, H. (1996). Women at the center. Dhaka, Bangladesh: University Press (cited in "Measuring the impact of microfinance: Taking stock of what we know" (2005). USA: Grameen Foundation).

UNAIDS. (2004). Report on the global AIDS epidemic. Geneva: UNAIDS.

UNAIDS. (2008). Report on the global AIDS epidemic. Geneva: UNAIDS.

UNDP Malawi. (2006). Malawi human development report 2005: Reversing HIV and AIDS in Malawi.

UNICEF, Bernard van Leer Foundation, CARE, \& et al. (2004). The framework for the protection, care and support of orphaned and vulnerable children living in a world with HIV and AIDS. http://www.unicef.org/aids/ files/Framework_English. pdf

UNICEF, UNAIDS, \& USAID. (2004). Children on the brink 2004: A joint report of new orphan estimates and a framework for action. New York: UNICEF.

Walker, S.P., Wachs, T.D., Gardner, J.M., Lozoff, B., Wasserman, G.A., Pollitt, E., et al. (2007). Child development in developing countries 2: Child development-risk factors for adverse outcomes in developing countries. Lancet, 369, 145-157.

World Bank. (1997). Confronting AIDS: Public priorities in a global epidemic. New York: Oxford University Press. 